Article

\title{
Hybrid Surface Nanostructures Using Chemical Vapor Deposition and Colloidal Self-Assembled Patterns for Human Mesenchymal Stem Cell Culture-A Preliminary Study
}

\author{
Yung-Chiang Liu ${ }^{1,+}\left(\mathbb{D}\right.$, Jhe-Wei Jhang ${ }^{1,2,+}{ }^{,}$Kun Liu ${ }^{1}\left(\mathbb{D}\right.$, Haobo Pan ${ }^{1}$, Hsien-Yeh Chen ${ }^{3,4, *}$ (D) \\ and Peng-Yuan Wang 1,5,6,*iD
}

Citation: Liu, Y.-C.; Jhang, J.-W.; Liu, K.; Pan, H.; Chen, H.-Y.; Wang, P.-Y. Hybrid Surface Nanostructures Using Chemical Vapor Deposition and Colloidal Self-Assembled Patterns for Human Mesenchymal Stem Cell Culture-A Preliminary Study. Coatings 2022, 12, 311. https://doi.org/10.3390/ coatings12030311

Academic Editor: Roman A. Surmenev

Received: 23 December 2021 Accepted: 7 February 2022 Published: 25 February 2022

Publisher's Note: MDPI stays neutral with regard to jurisdictional claims in published maps and institutional affiliations.

Copyright: (C) 2022 by the authors. Licensee MDPI, Basel, Switzerland. This article is an open access article distributed under the terms and conditions of the Creative Commons Attribution (CC BY) license (https:// creativecommons.org/licenses/by/ $4.0 /)$.

1 Shenzhen Key Laboratory of Biomimetic Materials and Cellular Immunomodulation, Shenzhen Institute of Advanced Technology, Chinese Academy of Sciences, Shenzhen 518055, China; alanliu1228@gmail.com (Y.-C.L.); zw.zhang2@siat.ac.cn (J.-W.J.); Kun.liu1@siat.ac.cn (K.L.); hb.pan@siat.ac.cn (H.P.)

2 Shenzhen Institute of Advanced Technology, University of Chinese Academy of Sciences, Beijing 100049, China

3 Department of Chemical Engineering, National Taiwan University, Taipei 10617, Taiwan

4 Advanced Research Center for Green Materials Science and Technology, National Taiwan University, Taipei 10617, Taiwan

5 Oujiang Laboratory, Wenzhou 325000, China

6 Key Laboratory of Alzheimer's Disease of Zhejiang Province, Institute of Aging, Wenzhou Medical University, Wenzhou 325000, China

* Correspondence: hsychen@ntu.edu.tw (H.-Y.C.); py.wang@ojlab.ac.cn (P.-Y.W.)

$\dagger$ These authors contributed equally to this work.

\begin{abstract}
Surface coatings are critical in biomaterials and biomedical devices. Chemical vapor deposition (CVD) is a well-known technology for the generation of thin films on a surface. However, the granular structures produced using CVD are rare. Recently, we used PPX-C, an excellent insulating material, for granular structure coating using CVD. Colloidal self-assembly is also a well-established method to generate granular structures named colloidal self-assembled patterns (cSAPs). In this study, we combined these two technologies to generate hierarchical granular structures and tested the biophysical effect of these hybrid surfaces on human bone marrow mesenchymal stem cells (hBMSCs). Two CVD-derived granular structures were made using water or glycerin droplets (i.e., CVD or GlyCVD surfaces). Water drops generate porous particles, while glycerin drops generate core-shell particles on the surface. These particles were dispersed randomly on the surface with sizes ranging from 1 to $20 \mu \mathrm{m}$. These CVD surfaces were hydrophobic (WCA 80-110 degrees). On the other hand, a binary colloidal crystal (BCC), one type of cSAPs, composed of $5 \mu \mathrm{m}$ Si and $400 \mathrm{~nm}$ carboxylated polystyrene (PSC) particles, had a close-packed structure and a hydrophilic surface (WCA 45 degrees). The hybrid surfaces (i.e., CVD-BCC and GlyCVD-BCC) were smooth ( $\mathrm{Ra} \sim 1.1-1.5 \mu \mathrm{m})$ and hydrophilic (WCA $~ 50$ degrees), indicating a large surface coverage of BCC dominating the surface property. The hybrid surfaces were expected to be slightly negatively charged due to naturally charged CVD particles and negatively charged BCC particles. Cell adhesion was reduced on the hybrid surfaces, leading to an aggregated cell morphology, without reducing cell activity, compared to the flat control after 5 days. qPCR analysis showed that gene expression of type II collagen (COL2) was highly expressed on the GlyCVD-BCC without chemical induction after 3 and 14 days compared to the flat control. This proof-of-concept study demonstrates the potential of combining two technologies to make hybrid structures that can modulate stem cell attachment and differentiation.
\end{abstract}

Keywords: chemical vapor deposition; binary colloidal crystals; mesenchymal stem cell; biophysics; type II collagen 


\section{Introduction}

Ideal biomaterials should have optimized physicochemical properties and good biological properties. The interaction between materials and cells affects their biological characteristics, such as proliferation, differentiation, inflammation, carcinogenesis, or thrombosis [1]. Therefore, controlling and improving the surface properties of biomaterials is crucial in biomedical applications [2].

Chemical vapor deposition (CVD) uses gaseous or vaporous substances to chemically react on a solid surface to generate solid deposits [3,4]. The thermal decomposition reaction in CVD deposition reaction deposits the target product on the substrate in a single-temperature zone tube furnace, which in turn decomposes the solid compound by heating and passes the gas by-product into a vacuum or inert gas [5,6]. CVD technology is often used for thin-film generation in the semiconductor industry $[7,8]$. However, CVD technology has rarely been applied to generate three-dimensional (3D) structured surfaces.

Poly(para-xylylene) (PPX) is an outstanding CVD material that was developed in 1966 [9]. The derivatives of PPX include PPX-N, without any substituents, and PPX-C and PPX-D, with chlorine in the para position of the benzene ring instead of the hydrogen element [10]. In application, PPX is mainly used in the form of thin films, e.g., as an insulating protective layer used in the semiconductor industry. In recent years, the excellent bioinert and biocompatibility of PPX and its derivatives have made it a great material for use in biomedical devices [11]. For example, PPX-C has excellent electrical properties, heat resistance, and chemical stability, which is desired in various applications such as moisture protection for circuit boards, sensors, or medical instruments and corrosion protection for metals [12]. Recently, our group has developed an approach to make porous granular PPX-C structures using two simultaneous dynamic competition processes of material sublimation and deposition $[4,13]$. The porosity and pore size can be controlled by the temperature and speed of gas flow during the deposition process [4].

Colloidal self-assembly is a well-established method that generates granular structures named colloidal self-assembled patterns (cSAPs). Binary colloidal crystals (BCCs), one type of CSAPs, which have highly ordered surface structures [14], are composed of two different types of colloidal particles $[15,16]$. The surface of BCCs can present both organic and inorganic components, micro- and nanostructures, and abundant physicochemical properties such as different particle sizes and chemical compositions $[14,17,18]$. BCCs can be biochemically modified to equip the surface with various bioactivities, simulating the extracellular matrix (ECM) for cell attachment [16,19]. The complex surface properties of BCCs are beneficial in regulating cell adhesions and stem cell differentiation $[17,20]$. Our previous studies proved that BCCs could manipulate the proliferation and differentiation of stem cells via controlling focal adhesions depending on the combination of particles $[17,21-23]$. BCCs have 2.5D surface structures that can tune cell morphology from fully spread to spherical depending on the surface properties.

For the first time, this study combines two technologies to build new types of hybrid surfaces. Cell adhesion and the gene expression of human bone mesenchymal stem cells (hBMSCs) were investigated on the hybrid surfaces, CVD-BCC and GlyCVD-BCC, over 14 days. This proof-of-concept study explores the potential of combining two well-known technologies and reveals its effect on hBMSC culture.

\section{Materials and Methods}

\subsection{CVD and GlyCVD Fabrication}

PPX-C (LaChi Enterprise CO., LTD., Taiwan, China) was used as the material to form particles on a surface, according to our previous study [4]. Briefly, PPX-C was vaporized at $670{ }^{\circ} \mathrm{C}$ and inerted with argon. The other end of the pipe was a polystyrene (PS)coated glass slide. Tiny water drops were sprayed on the glass slides at low temperatures (i.e., $-186^{\circ} \mathrm{C}$ ) to form ice drops (Figure 1A). The ice particles acted as templates to form porous PPX-C particles during the CVD process [24], named CVD samples in this study. 
(A)

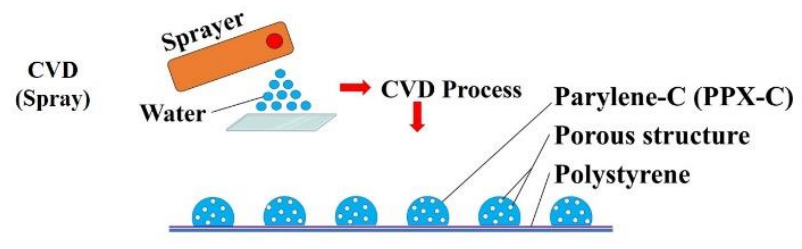

(B)

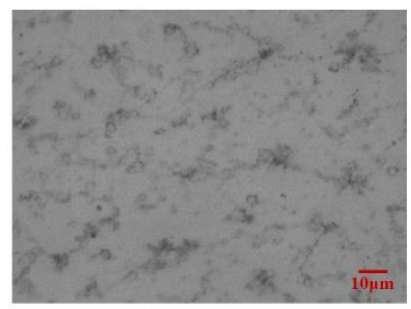

(C)
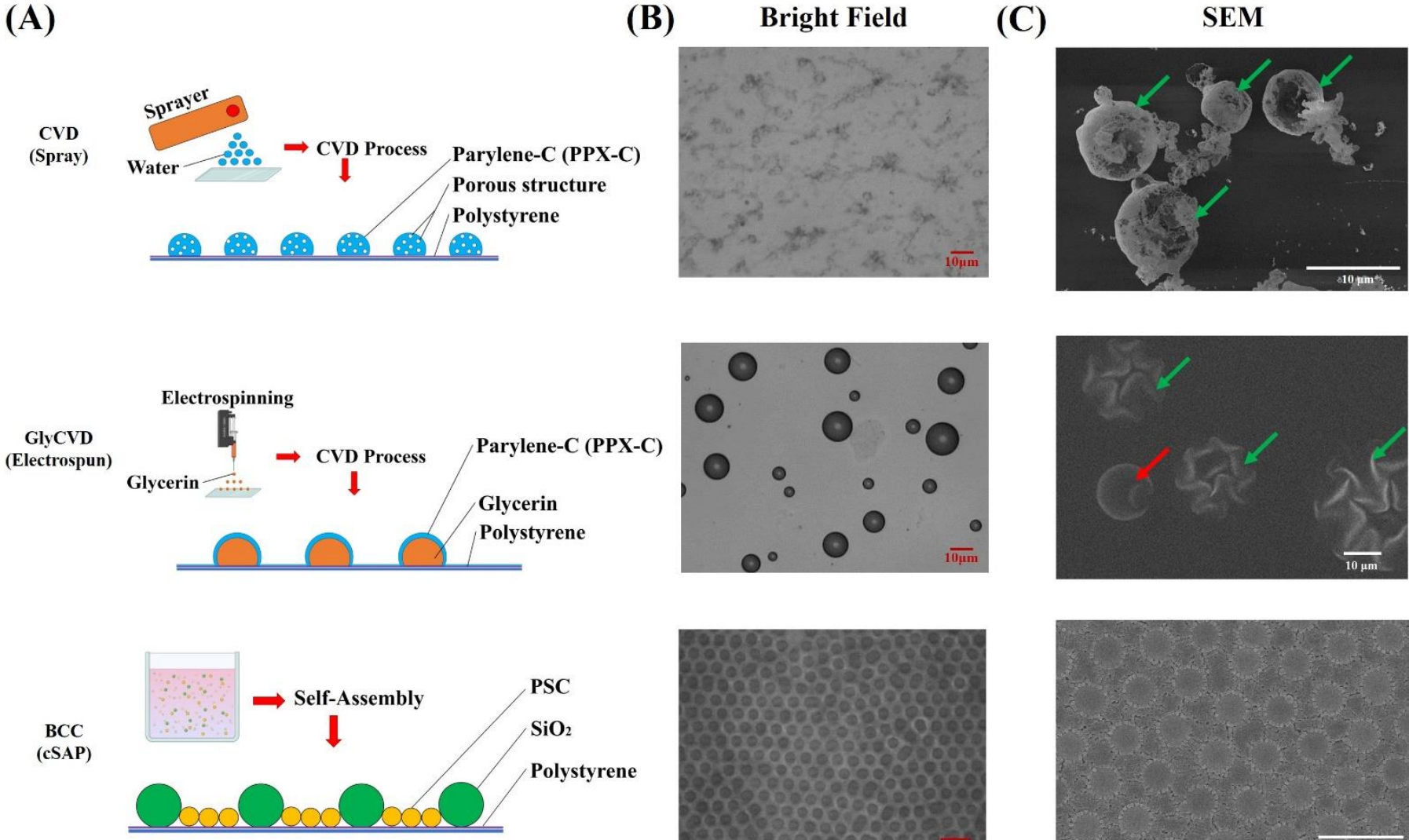

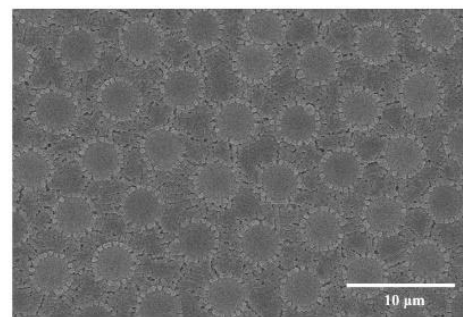

Figure 1. (A) Schematic illustration of the fabrication of granular structured surfaces including CVD, GlyCVD, and BCC structures. (B) Bright-field images of three types of surfaces. (C) SEM images of three types of surfaces. Scale bars $=10 \mu \mathrm{m}$. Arrows indicate the CVD and GlyCVD particles. Green arrows indicate damaged particles in high vacuum conditions or sputtering treatment. CVD particles were broken while GlyCVD particles were shrunk. The red arrow indicates an intact GlyCVD particle.

Meanwhile, glycerin drops were sprayed on the PS-coated glass slides using electrospinning technology (Figure 1A). This study used the same CVD process for PPX$\mathrm{C} /$ glycerin core-shell particles, named GlyCVD samples.

\subsection{BCC and the Hybrid Surface Fabrication}

Two types of particles, Si $5 \mu \mathrm{m}$ and PSC $0.4 \mu \mathrm{m}$, were used for binary colloidal crystal (BCC) fabrication according to our previous study [14]. Briefly, two types of particles were mixed in DI water and added to a confined area to cover the glass slide in a monolayer. Then, samples were heated at $200{ }^{\circ} \mathrm{C}$ for $1 \mathrm{~min}$ to stabilize the BCCs [17].

The hybrid surfaces, CVD-BCC and GlyCVD-BCC, were fabricated using a two-step method. CVD and GlyCVD samples were fabricated first and used as substrates for BCCs. Then, the hybrid surfaces were heated at $200{ }^{\circ} \mathrm{C}$ for $1 \mathrm{~min}$ to stabilize the particles.

\subsection{Surface Characterization}

The surface structure was characterized using a field emission scanning electron microscope (FE-SEM, Zeiss SUPRA ${ }^{\circledR} 55$, Jena, Germany) and a 3D laser scanning microscope (LSM, keyence VK-9510, Osaka, Japan). Samples for SEM were coated with a thin layer of gold prior to observation. Surface roughness was analyzed using LSM and software (VK Image Analyzer, Japan). 


\subsection{Cell Culture and Activity Test}

Human fetal bone marrow mesenchymal stem cells (hBMSCs) were purchased from Cyagen Biosciences (HUXMF-01001, Suzhou Inc., Suzhou, China) at passage 2. Cells were routinely maintained in the complete growth media (HUXMF-90011, Cyagen Bioscience, Suzhou, China). Cell activity was determined by the CCK-8 kit according to the manufacturer's instructions. The CCK-8 solution was added to each well and incubated at $37^{\circ} \mathrm{C}$ for $2 \mathrm{~h}$. Six samples were analyzed in each experiment $(n=6)$. The optical density of the formazan solution was read at $450 \mathrm{~nm}$ using a high-quality, monochromator-based UV/VIS spectrophotometer (Multiskan GO, Thermo Scientific, Waltham, MA, USA).

\subsection{Immunofluorescence Staining}

Cells were fixed with $4 \%$ paraformaldehyde (PFA) in phosphate-buffered saline (PBS) for $20 \mathrm{~min}$ at room temperature and permeabilized with $0.1 \%$ Triton-X 100 for $10 \mathrm{~min}$. Cells were then incubated with the primary antibodies overnight at $4{ }^{\circ} \mathrm{C}$. F-actin (Flash Phalloidin $^{\mathrm{TM}}$ Green 488 (424201, BioLegend, San Diego, CA, USA)) or anti-vinculin (ab129002, abcam, Cambridge, UK) were used for cytoskeleton and focal adhesion staining. The secondary antibody, goat anti-rabbit IgG H\&L (Alexa Fluor $555^{\circledR}$, ab150178, abcam, Cambridge, UK), was then used for $1 \mathrm{~h}$ at $37^{\circ} \mathrm{C}$. The cell nucleus was stained using Hoechst 33,342 nucleic acid staining solution (1:2000, H3570, Invitrogen, Waltham, MA, USA). Images were captured using an inverted fluorescence microscope (CKX53, Olympus, Tokyo, Japan) with the MetaVueTM imaging system. Measurements of the cell size were performed with ImageJ software (National Institutes of Health, Bethesda, MD, USA) as previously described.

\subsection{Real-Time PCR}

RNA was isolated with Trizol (Invitrogen, USA) according to the manufacturer's instructions. cDNA was produced using the iScript cDNA Synthesis Kit (170-8891, BioRad, Hercules, CA, USA). Real-time PCR was conducted using the SYBR green PCR kit (170-8882AP, Bio-Rad, Hercules, CA, USA) and performed on a ROCHE Real-Time PCR System (ROCHE LightCycler ${ }^{\circledR} 96$ System, Basel, Swiss). Genes of three mesenchymal lineages, bone (ALP and RUNX2), cartilage (COL2A1, ACAN), and fat (PPARG, CIDEC) were analyzed. Primers are listed in Table 1 . Each target gene was normalized to the reference gene glyceraldehyde phosphate dehydrogenase (GAPDH), and the expression was normalized to the flat controls. Data were analyzed by the threshold cycle number $(\mathrm{Ct})$ relative quantification method with the ROCHE LightCycler ${ }^{\circledR} 96 \mathrm{SW}$ 1.1. The relative gene expression was calculated using the $2^{-\Delta \Delta C t}$ method. Three biological $(n=3)$ and three technical repeats were conducted.

Table 1. Primer sequences for $\mathrm{qPCR}$.

\begin{tabular}{|c|c|c|}
\hline Gene & Forward & Reverse \\
\hline ALP & $5^{\prime}$ - CCACGTCTTCACATTTGGTG -3' & $5^{\prime}$ - CAGACTGCGCCTGGTAGTTG -3' \\
\hline RUNX2 & 5'- TGCACTGGGTCATGTGTTTG -3' & 5'- TGGCTGCATTGAAAAGACTG -3' \\
\hline COL2A1 & $5^{\prime}$ - AAGGCTCCCAGAACATCACC $-3^{\prime}$ & $5^{\prime}-$ ATCCTTCAGGGCAGTGTACG -3' \\
\hline ACAN & $5^{\prime}-$ TCTGTAACCCAGGCTCCAAC $-3^{\prime}$ & $5^{\prime}$ - TGGAGTACCTGGTGGCTCTC $-3^{\prime}$ \\
\hline PPARG & $5^{\prime}$ - AGCCTCATGAAGAGCCTTCCA - $3^{\prime}$ & $5^{\prime}-$ TCCGGAAGAAACCCTTGCA - $3^{\prime}$ \\
\hline CIDEC & $5^{\prime}$ - CAGCAGCTCCTCGATGCTAC -3' & $5^{\prime}$ - TCAGACAGGTCGGGATAAGGG -3' \\
\hline
\end{tabular}

\subsection{Statistical Analysis}

Data are expressed as the mean values \pm standard deviation (SD) from each independent experiment. Each experiment was repeated at least three times. The results were analyzed by one-way analysis of variance (ANOVA). The statistical significance between the experimental groups was determined by the Student's $t$-test (Sigmaplot V10.0) and indicated as: ${ }^{*} p<0.05,{ }^{* *} p<0.01$, and ${ }^{* * *} p<0.001$. The cartoon was created with BioRender. 


\section{Results and Discussion}

\subsection{New Hybrid CVD-BCC and GlyCVD-BCC Structures}

New hybrid structures were fabricated using two technologies, CVD and CSAP, and characterized (Figure 1A). First of all, two CVD substrates were fabricated. CVD particles generated using water/ice drops had $5 \mu \mathrm{m}$ diameters on average, ranging from $1 \mu \mathrm{m}$ to $10 \mu \mathrm{m}$ (Figure 1B,C). GlyCVD particles generated using glycerin drops were much bigger with an average size of $10 \mu \mathrm{m}$, ranging from $2 \mu \mathrm{m}$ to $20 \mu \mathrm{m}$ bigger than CVD particles (Figure 1B,C). It should be noted that the high vacuum condition during SEM observation resulted in the breakage and shrinkage of the CVD and GlyCVD particles, respectively (Figure 1C). This phenomenon could be due to the brittle and porous structure of CVD particles and the evaporation of glycerin within GlyCVD particles. Both samples had randomly distributed particles on their surfaces. CVD particles were small and porous, while GlyCVD particles were large without pores (or sub-nanometer pores). The difference between them can be found in the SEM images (Figure 1C).

Second, a binary colloidal crystal (BCC) was fabricated, which contained two types of particles. The BCC surface had a close-packed structure and highly ordered particles in a monolayer (Figure 1C). The surface of BCC was hydrophilic (water contact angle (WCA) 43 degrees), while two CVD surfaces were hydrophobic (WCA 88-111 degrees) (Figure 2). Finally, BCC was fabricated on two CVD substrates to form two hybrid surfaces, CVD-BCC and GlyCVD-BCC.

The surface wettability of the two hybrid surfaces was hydrophilic with similar WCA to the BCC. In addition, the surface roughness of BCC was low $(\mathrm{Ra} \sim 0.7 \mu \mathrm{m})$ while that of the CVD surfaces was high ( $\mathrm{Ra} \sim 1.1-1.5 \mu \mathrm{m}$ ) (Figure 3). This indicates that the BCC occupies a large surface area and dominates the surface property of the hybrid surfaces. Indeed, the surface roughness will affect surface wettability [25,26]. The wettability between the two hybrid surfaces is similar, but the roughness is slightly different, indicating that surface roughness and particle distribution could be the main factors affecting cell adhesion and cellular response.

The physicochemical properties of the hybrid surfaces are rich. For example, PPX-C is hydrophobic, while BCC particles are hydrophilic. Surfaces of CVD and GlyCVD are roughed while BCC is smooth. PPX-C is electroneutral, while BCC particles are negatively charged. Surface wettability is determined by surface charge, topography, and hydrophilicity. Since the hybrid surfaces are mainly covered by BCC, the surface wettability between the two hybrid surfaces is similar. The relationship between roughness and wettability is complex. There are two main models to explain this relationship, the Wenzel and CassieBaxter models. When the surface is hydrophilic, surface roughness increases, leading to a lower WCA than the flat control. On the other hand, when the surface is hydrophobic, an increase in surface roughness leads to a higher WCA than the flat control. The property of hybrid surfaces can be explained using the Wenzel model due to a low WCA.

For the first time, we encapsulated oil substances (i.e., glycerin), within CVD particles following our previous study [4]. In our previous studies, many dopants were tested, including inorganic $\mathrm{Au}, \mathrm{Ag}$, and Fe oxides, carbon dioxide, and organic solvents, such as methanol, ethanol, acetone, and hexane. These dopants were classified into two categories of "volatile" and "non-volatile" during the thermodynamic processing conditions (approximately 0.1 bar and room temperature or below). We found that the fabricated porous polymer products were significantly impacted with their mechanical properties, e.g., pore size, porosity, Young's modulus, etc., by "volatile" dopants due to the sublimation (volatility) $[27,28]$. The mechanical properties can be tunable in a wide range; for instance, Young's modulus can be tuned from $100 \mathrm{kPa}$ to $10 \mathrm{MPa}$, by tuning pore sizes and porosities $(50 \%-80 \%)$. By contrast, the "non-volatile" dopants showed negligible impact to the mechanical properties of fabricated porous products due to (i) non-sublimating behavior and (ii) a small number of dopants compared to the polymer matrix. The overall mechanical properties were assumed consistent with a blank porous product (only with a polymer 
matrix). Considering that the glycerin used in the current study was in the "non-volatile" category, the impact of glycerin on the overall mechanical properties could be negligible.

(A)
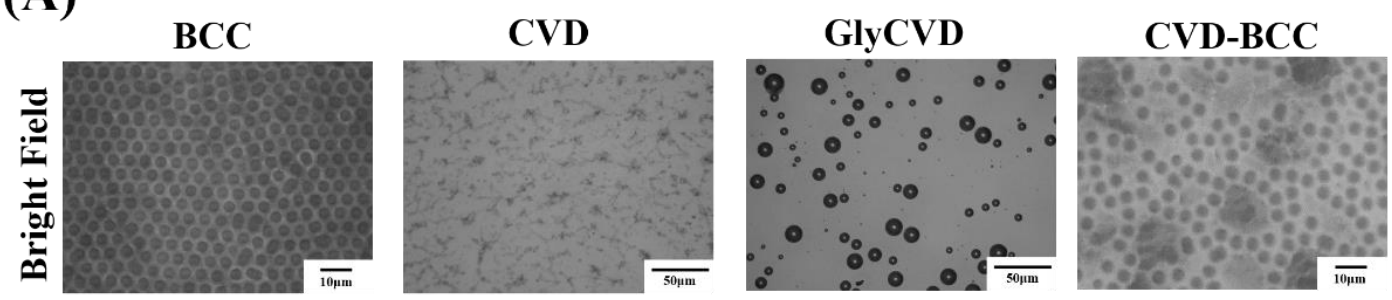

\section{GlyCVD-BCC}

(B)
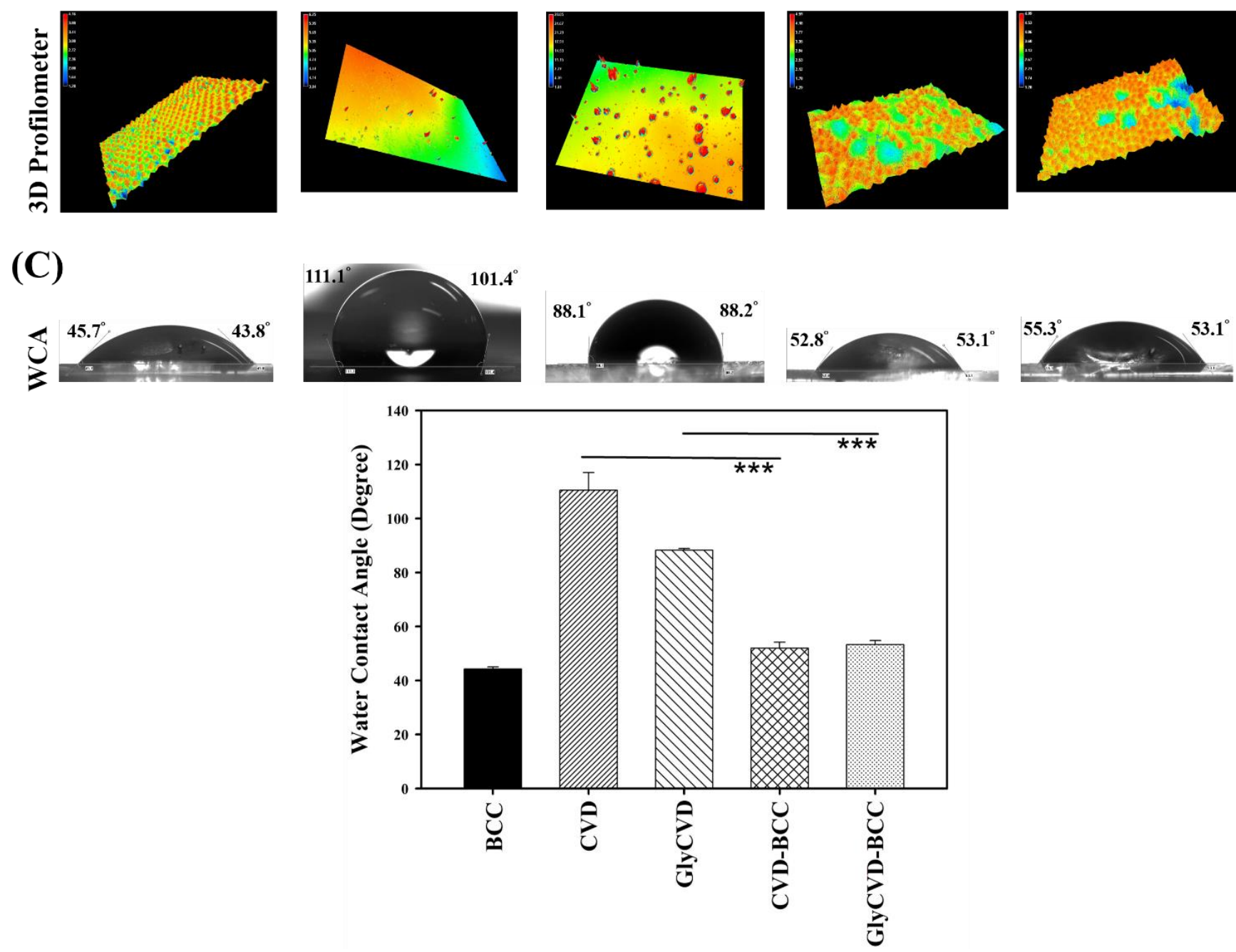

Figure 2. Surface characterization using (A) inverted microscope, (B) laser 3D profilometer, and (C) water contact angle analysis. Five types of structured surfaces were fabricated and characterized. BCC has close-packed structures while CVD and GlyCVD do not. The hybrid surfaces, CVD-BCC and GlyCVD-BCC, have close-packed and hierarchical structures. BCC is hydrophilic while CVD and GlyCVD are hydrophobic. Asterisks denote significant differences in the water contact angle $(* * *<0.001)$.

For the first time, we developed a feasible two-step approach to fabricate new nanostructured surfaces using CVD and cSAPs. By tuning the fabrication process and materials, more hybrid surfaces can be designed and fabricated. Furthermore, both CVD and BCC technology are feasible to modify the particles with biological signals such as peptides and 
saccharides [29]. This approach opens the door for the fabrication of more advanced microand nanostructures in a short period. Next, we analyze whether these new hybrid surfaces could affect stem cell growth and gene expression.

(A)
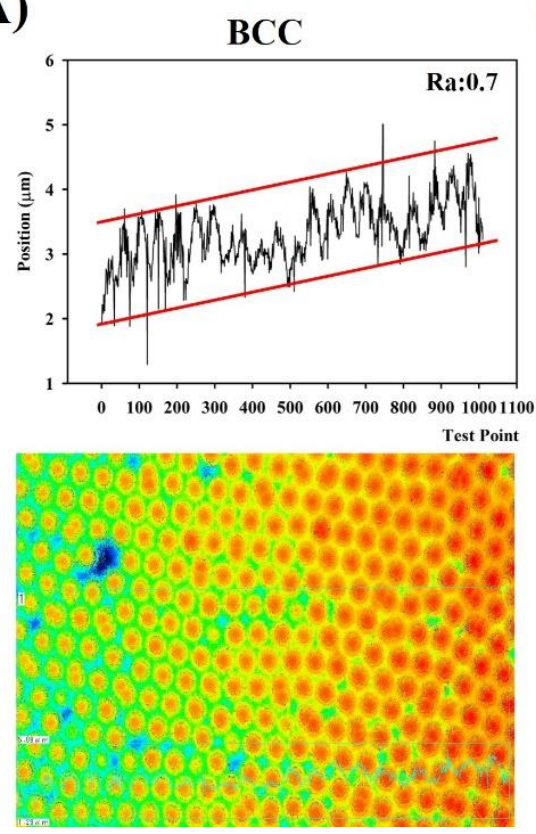

(B)
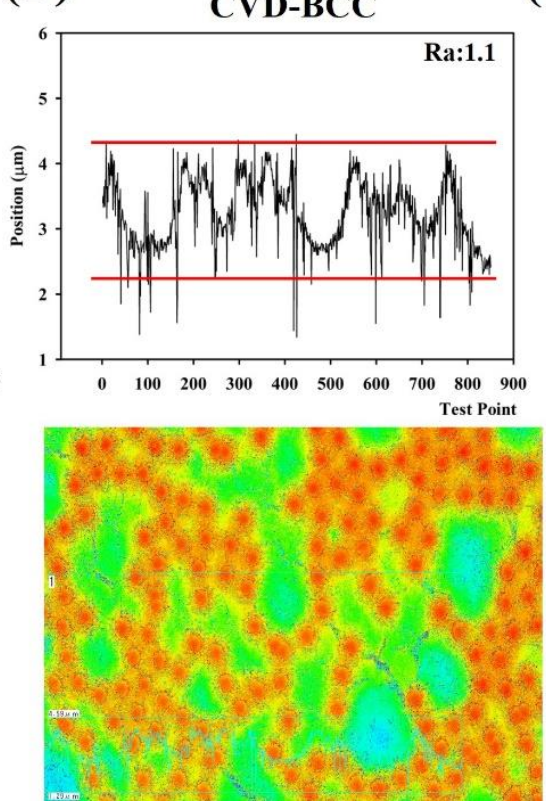

(C)
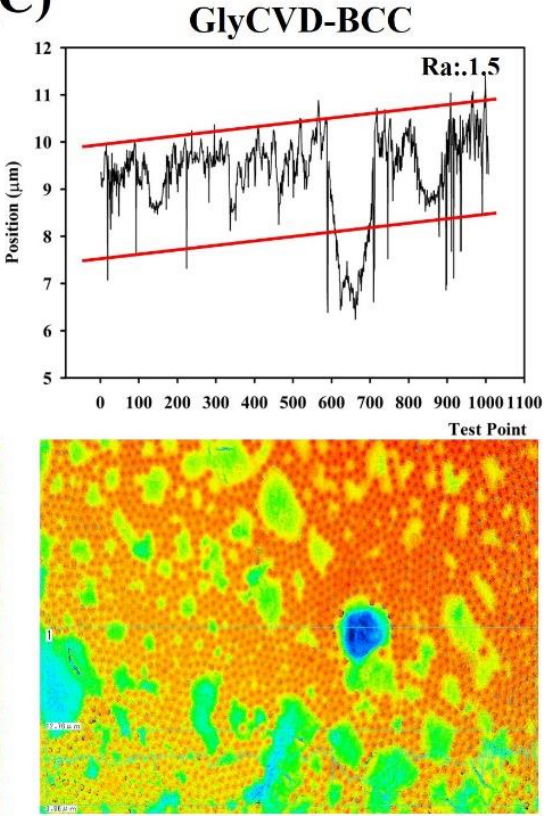

Figure 3. The surface structure and roughness of (A) BCC (B) CVD-BCC, and (C) GlyCVD-BCC were detected by laser 3D profilometer. A surface area around $1 \mathrm{~mm} \times 1 \mathrm{~mm}$ was imaged.

\subsection{Cell Morphology and Growth of hBMSCs on the Hybrid Structures}

Cells were cultured on the hybrid surfaces, CVD-BCC and GlyCVD-BCC, and tissue culture polystyrene (TCPS) as a flat control for 5 days. After 3 days, cells started forming clusters on the hybrid surfaces but not the flat control (Figure 4A). After 5 days, cells formed aggregates on the hybrid surfaces (Figure 4B). The results indicate that cell-surface interaction is weak, and cells tend to aggregate on the hybrid surfaces. It should be noted that cell aggregates were detached during sample treatments for immunostaining, such as multiple PBS rinses. The weak cell adhesion led to decreased cell density on the hybrid surfaces.

Bright-field images showed many cell aggregates on the hybrid surfaces, but not SEM images (Figure 5A,B). Again, the weak cell adhesion led to cell detachment during the fixing process of SEM observation. Cell activity analysis that did not need to rinse samples showed no difference between samples on day 3 and day 5 (Figure 5B). Therefore, we conclude that the hybrid surfaces did not harm the cell growth, although the images contained few cells. This is consistent with our observation of cell detachment during sample rinses.

Surface roughness and particle distribution are the main factors why the hybrid surfaces alter cell adhesion and morphology. According to our previous study, humaninduced pluripotent stem cells (hiPSCs) formed cell spheroids on unique BCC surfaces (PM but not PSC surfaces) [17]. We also demonstrated that particle material and distribution are important factors on the BCC surfaces $[16,21]$. Therefore, controlling the combination of particles within BCCs can alter cell morphology from fully spread to 3D spherical. It can be seen that the hybrid surfaces contain three types of particles, two BCC and one CVD/GlyCVD particle. CVD/GlyCVD particles are hydrophobic, reducing cell adhesion, although the particle density is low, and the particle number is few. 

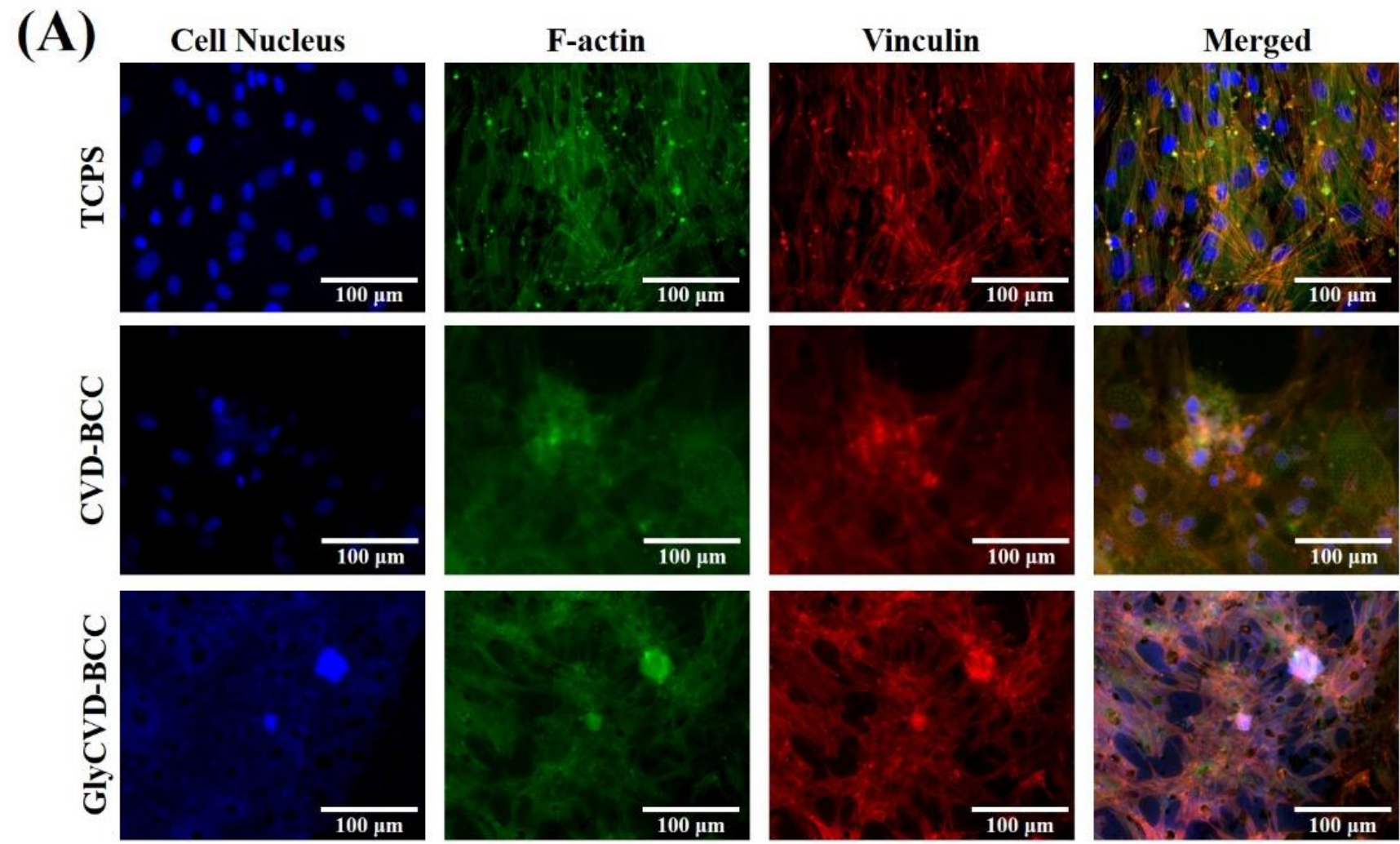

\section{(B) Cell Nucleus}

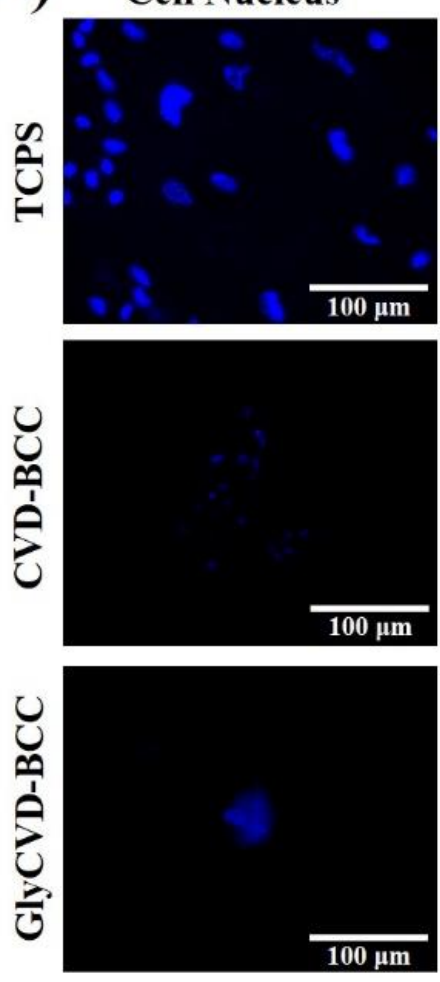

F-actin
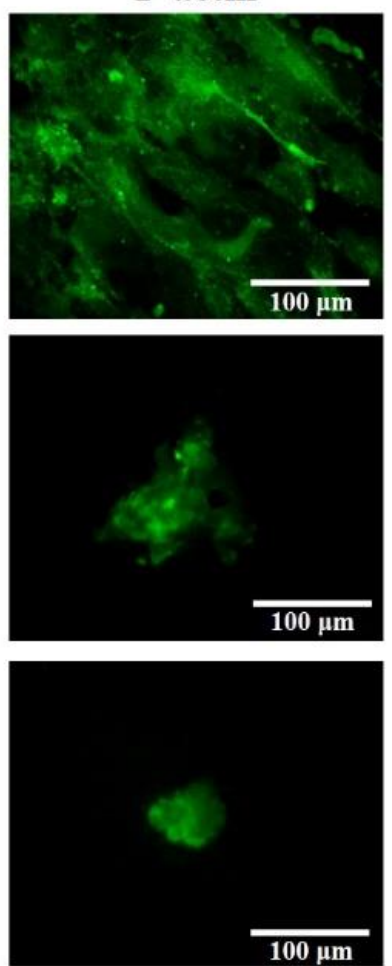

Vinculin
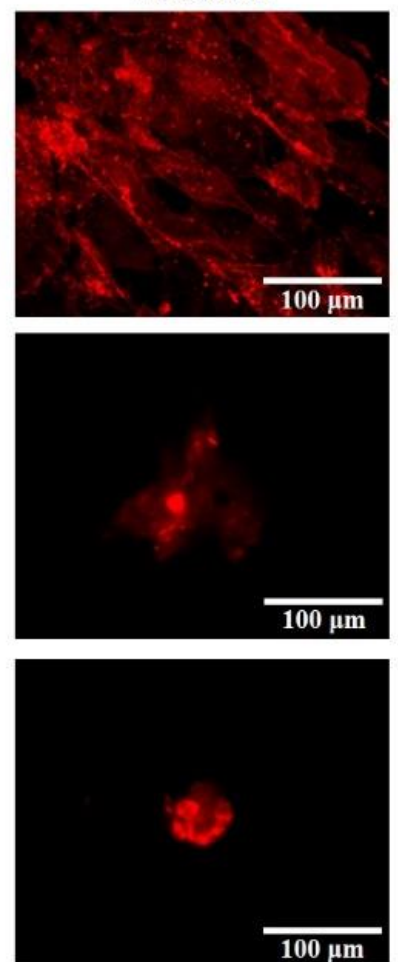

Merged
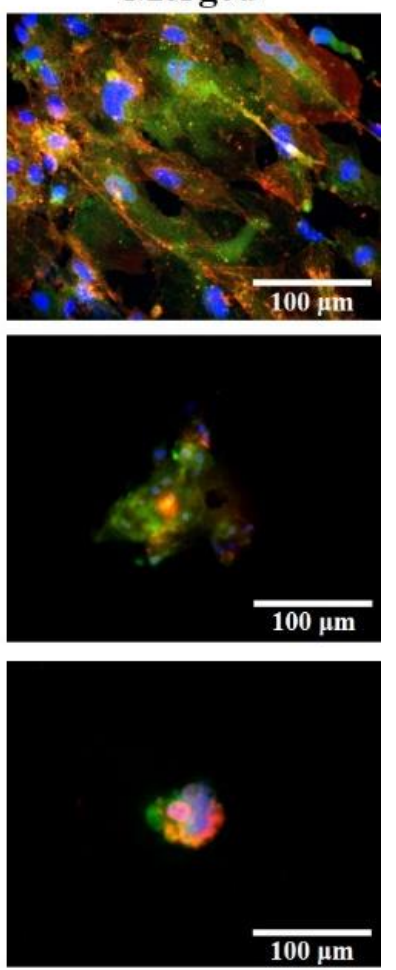

Figure 4. Representative images of cell morphology. The cell nucleus (DAPI), F-actin (Alex-488), and vinculin (phalloidin) of hBMSCs were immunostained after (A) 3 days and (B) 5 days. It should be noted that cell detachment was observed on the hybrid surfaces due to multiple rinses during staining. 

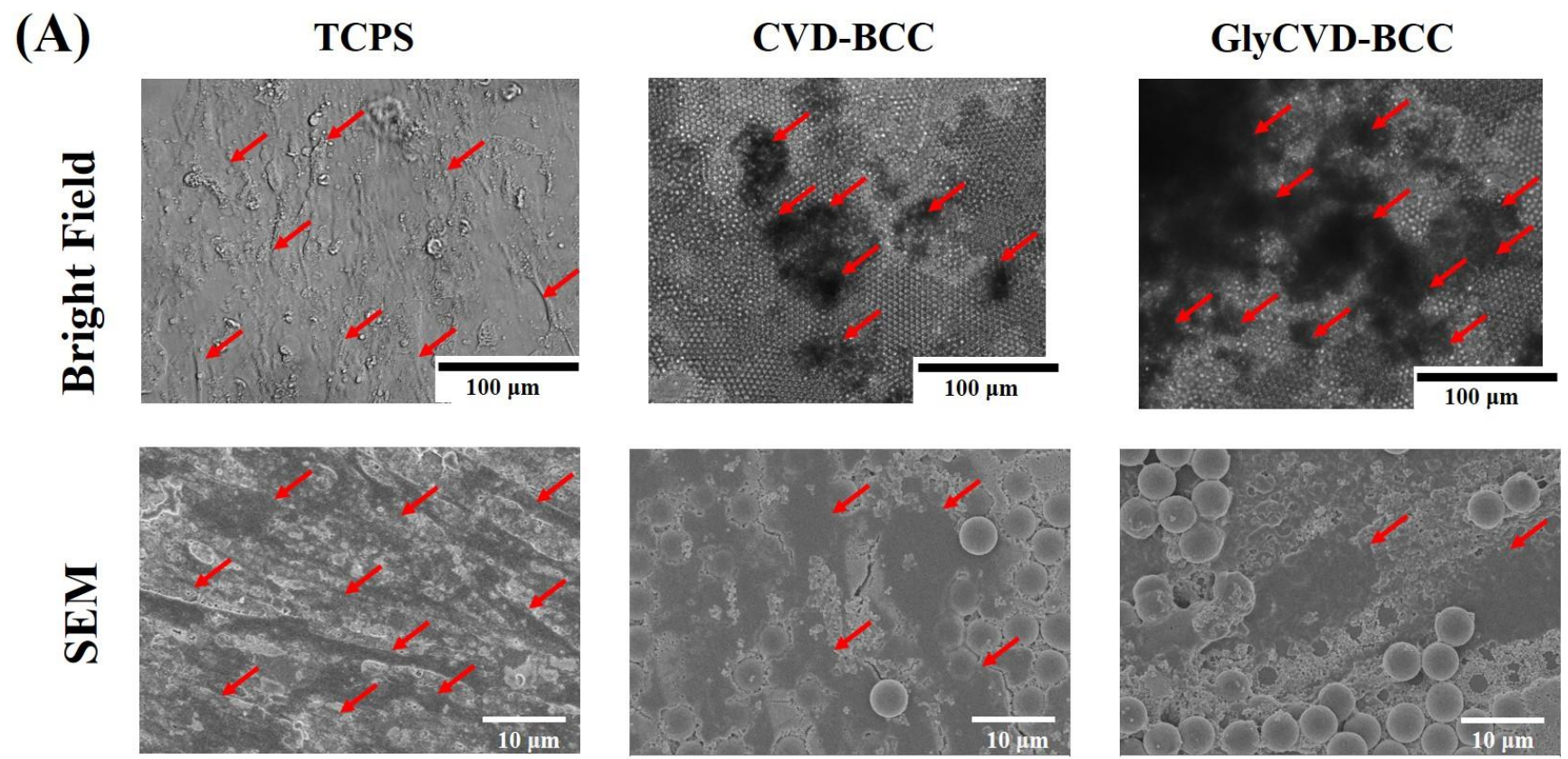

(B)

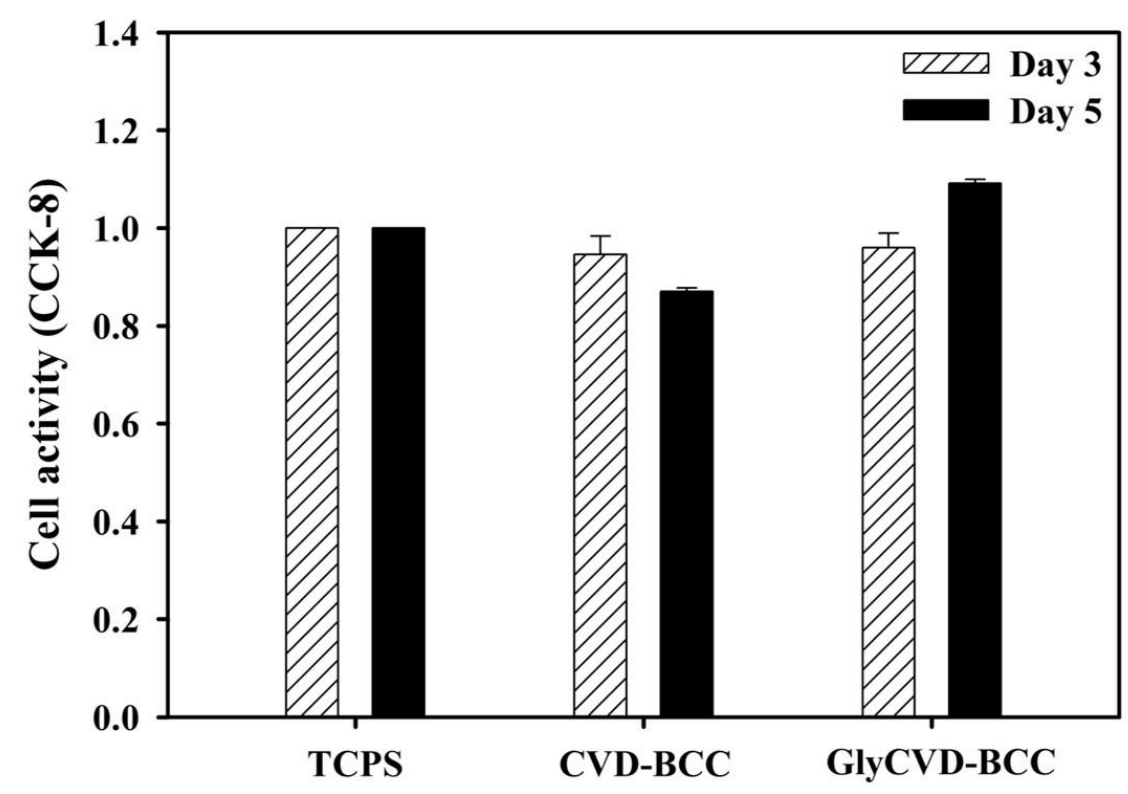

Figure 5. (A) Cell morphology of the hBMSCs cultured on TCPS, CVD-BCC, and GlyCVD-BCC at day 5. It should be noted that cells formed aggregates and detached after multiple rinses during the fixing process. Arrows indicate the cells. (B) Cell activity using CCK-8 analysis at day 3 and day 5 . Cell activity on the hybrid surfaces was normalized to the TCPS control $(n=6)$.

A previous study also showed that cell adhesion and morphology are strongly related to the material surface structure and property [18,30]. Cell adhesion can be tuned by controlling surface roughness, pore size, pore distribution, or wettability [31]. It should be noted that these physicochemical properties are often correlated to each other. For example, an increase in pore size will increase surface roughness. The relationship between roughness and wettability is even more complex, as discussed in Section 3.1. In this study, both hybrid surfaces were more hydrophilic than the TCPS control (WCA 65 degrees). Together with surface roughness and other surface properties, we conclude that the surface roughness and particle distribution were the main factors in controlling cell adhesion in this study. 
Anchor-dependent cells bind to the substrates via adhesion molecules such as integrins, whose intracellular domains such as talin and vinculin are connected to the cytoskeleton [32]. F-actins, fibrous actin polymerized in the form of a double-helix produced in the presence of a metal action and ATP, link the adhesion molecules on the cell membrane to those on the cell nucleus, such as Nesprin 1/2 and LINC complex [33,34]. In the cytoplasm, F-actin interacts with many proteins and even nanoparticles used for gene transfection and drug delivery [35]. F-actin plays an important role in stabilizing cell adhesion and regulating cell shape and cell movement. In this study, F-actin and vinculin were used to analyze cell-substrate interaction. On the TCPS surface, cells were spread out with more F-actin and vinculin; on the other hand, cells were rounded and aggregated on the hybrid surfaces, with less F-actin and vinculin, which is consistent with the previous studies [36,37]. Cell adhesion has a direct impact on the cell shape and the cytoskeleton. Cytoskeleton-related signaling pathways transmitted physical stimuli to the nucleus called mechanotransduction (outside-in signaling), affecting gene expression and cell fate. Therefore, cell fate can be tuned using different surface coatings.

Cell growth was not affected by the hybrid surfaces in this study. Although cells formed aggregates and may have detached from the hybrid surfaces, cell growth was not harmed. Previous studies showed that structured surfaces could suppress or prompt cell proliferation depending on the geometry [38-40]. We did not find any of these effects on the hybrid surfaces. Therefore, the effect of hybrid surfaces could be just at the transcription or epigenetic level. Next, we examine the gene expression of hBMSCs on the hybrid surfaces.

\subsection{Gene Expression of hBMSCs on the Hybrid Nanostructures}

Genes of three mesenchymal lineages, including bone, cartilage, and fat, were analyzed on day 3 and day 14. Cells were cultured within a standard growth medium; therefore, the effect of hybrid surfaces could be explored. Osteocyte genes (Alkaline Phosphatase (ALP) and RUNX Family Transcription Factor 2 (RUNX2)), chondrocyte genes (collagen II (COL2A1) and aggrecan (ACAN)), and adipocyte genes (peroxisome proliferator-activated receptor gamma (PPARG) and Cell Death Inducing DFFA Like Effector C (CIDEC)) were selected because these genes are essential differentiation genes of hBMSCs [41]. We found that both bone and fat genes were slightly upregulated on the GlyCVD-BCC surface at day 3 but downregulated at day 14 (Figure 6). On the other hand, one of the cartilage genes, COL2A1, was greatly upregulated on the GlyCVD-BCC surface compared to the flat control on day 3 ( $\sim 6$-fold) and day 14 ( 3-fold) (Figure 6). However, ACAN expression was downregulated at both time points.

COL2A1 is a crucial gene expressed in the early stage of chondrocyte differentiation of MSCs, which in turn generates type II collagen, the main protein of the cartilage ECM [42]. Type II collagen plays a critical role in articular cartilage due to its elasticity in joint function [41]. Aggrecan, a cartilage-specific proteoglycan core protein, also plays a key role in articular cartilage and joint function [41]. In the process of chondrocyte differentiation, COL2A1 was expressed significantly in the early stage of the differentiation process, while ACAN was expressed at the late stage, indicating a cartilage maturation [42,43]. According to the current results, COL2A1 is upregulated, but ACAN expression is suppressed on the GlyCVD-BCC surface. hBMSCs could be stimulated into pre-chondrocyte-like cells on the GlyCVD-BCC surface, but these cells are far from mature [42,43].

ALP expression is upregulated in the early stage and downregulated in the late stage of bone differentiation [44]. According to the results, the ALP gene was slightly upregulated at day 3, but downregulated at day 14 on the GlyCVD-BCC surface. However, RUNX2, a key transcription factor associated with osteoblast differentiation, was not changed across the surfaces, indicating no osteoblast differentiation initiated on the hybrid surfaces.

Cell aggregation may induce changes in gene expression, such as the upregulation of the COL2A1 gene $[40,45,46]$. Previous studies have shown that cell aggregation causes a significant increase in the gene expression of COL2A1 of hBMSCs which prompt chondrocyte differentiation $[47,48]$. Therefore, although cells formed aggregates and expressed the 
COL2A1 gene on the GlyCVD-BCC surface, we cannot conclude a chondrocyte differentiation due to a persistent downregulation of ACAN.

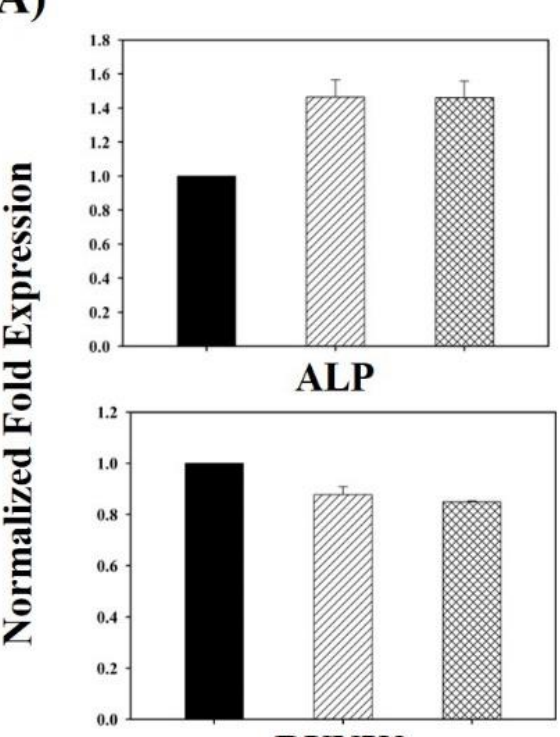

RUNX2

(B)
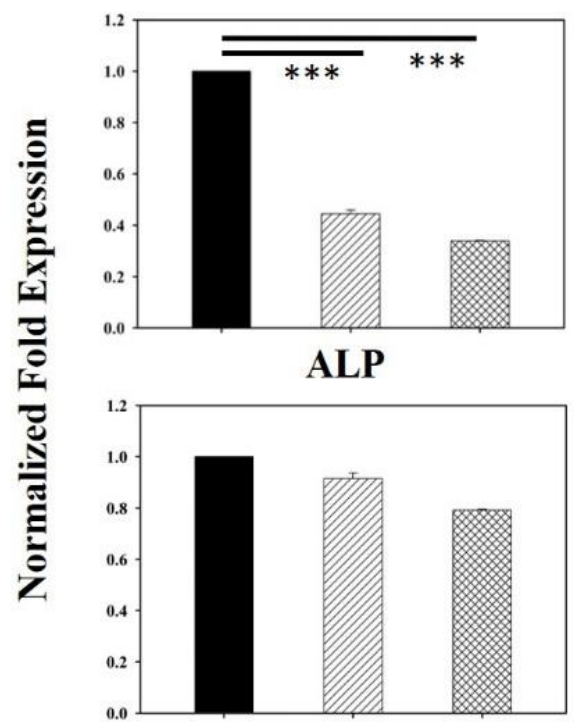

RUNX2

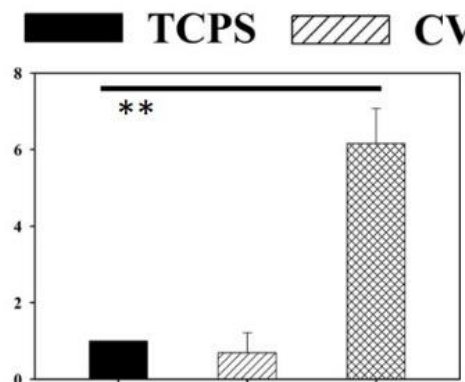

COL2A1

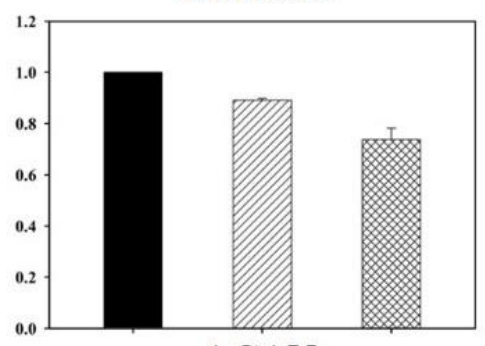

ACAN
GlyCVD-BCC

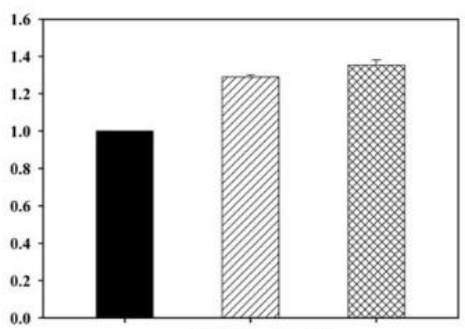

PPARG

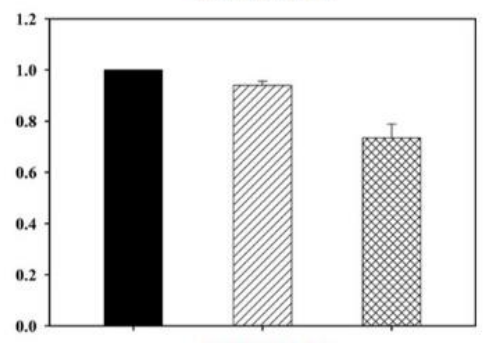

CIDEC

TCPS UIIT CVD-BCC GlyCVD-BCC

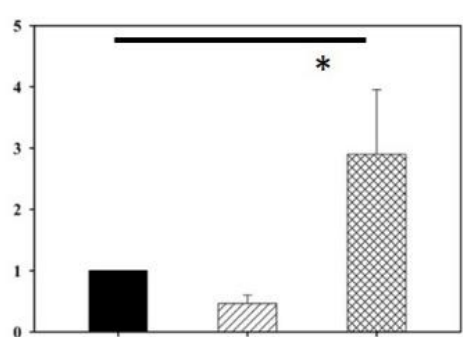

COL2A1

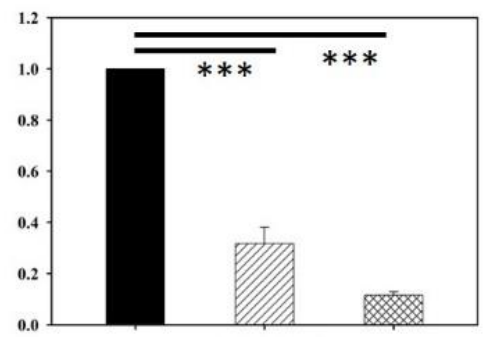

ACAN

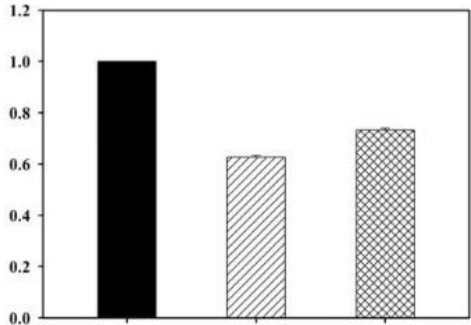

PPARG

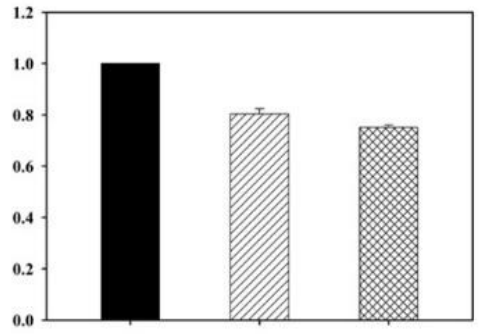

CIDEC

Figure 6. Gene expression of osteocyte genes (ALP and RUNX2), chondrocyte genes (COL2A and ACAN), and adipocyte genes (PPARG and CIDEC) of hBMSCs cultured on TCPS, CVD-BCC, and GlyCVD-BCC surfaces after (A) 3 days and (B) 14 days of culture. Asterisks denote significant differences between samples $(n=3) .{ }^{*} p<0.05,{ }^{* *} p<0.01$, and ${ }^{* * *} p<0.001$.

COL2 is important in many biological processes such as ECM synthesis, cellular responses to hormones, and mechanical stimulus [49-52]. In cellular responses to hormones, a previous study revealed reduced COL2 expression in the hypothyroid rat ovary, with a concomitant increase in COL2 degradation [51]. In another study, stem cell therapy decreased the necrosis and ulcerations of the bronchial stump in a rat model after pneumonectomy using adipose-derived stem cells (ASCs). A phenomenon was found where ASCs significantly increased the expression of COL2A1 after 10 days but decreased after 20 days [52]. A 
previous study showed that hMSCs produced more ECM on biomaterials' unique surfaces or environments [53]. hMSCs secrete ECM proteins into the pericellular space as soon as encapsulation using poly(ethylene glycol) (PEG) hydrogels occurs [53]. These results show a close relationship between the cell-attached substrate, COL2 expression, and stem cell functions.

Cumulative studies have shown that biophysical cues from the surfaces of biomaterials have a unique role in altering stem cell behavior [31,54]. Surface topography induces focal adhesion changes through receptors on the cell membrane. Mechanotransduction is then triggered and transmits forces to the cell nucleus through the cytoskeleton. This process will affect gene expression in the cell nucleus by stress and nuclear deformation and the epigenetic state and chromatin function [55-57]. Overall, this study demonstrates that combining two advanced technologies can generate hybrid nanostructures that could stimulate stem cells at the transcriptome level (Scheme 1).

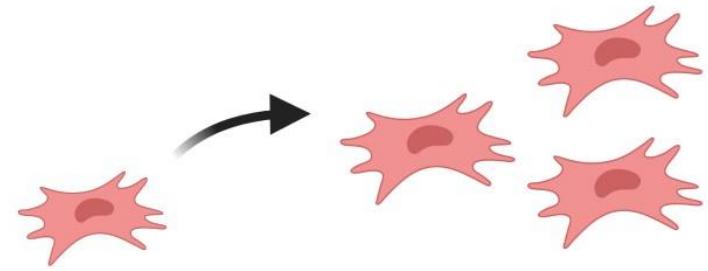

\section{human bone marrow} mesenchymal stem cells (hBMSCs)
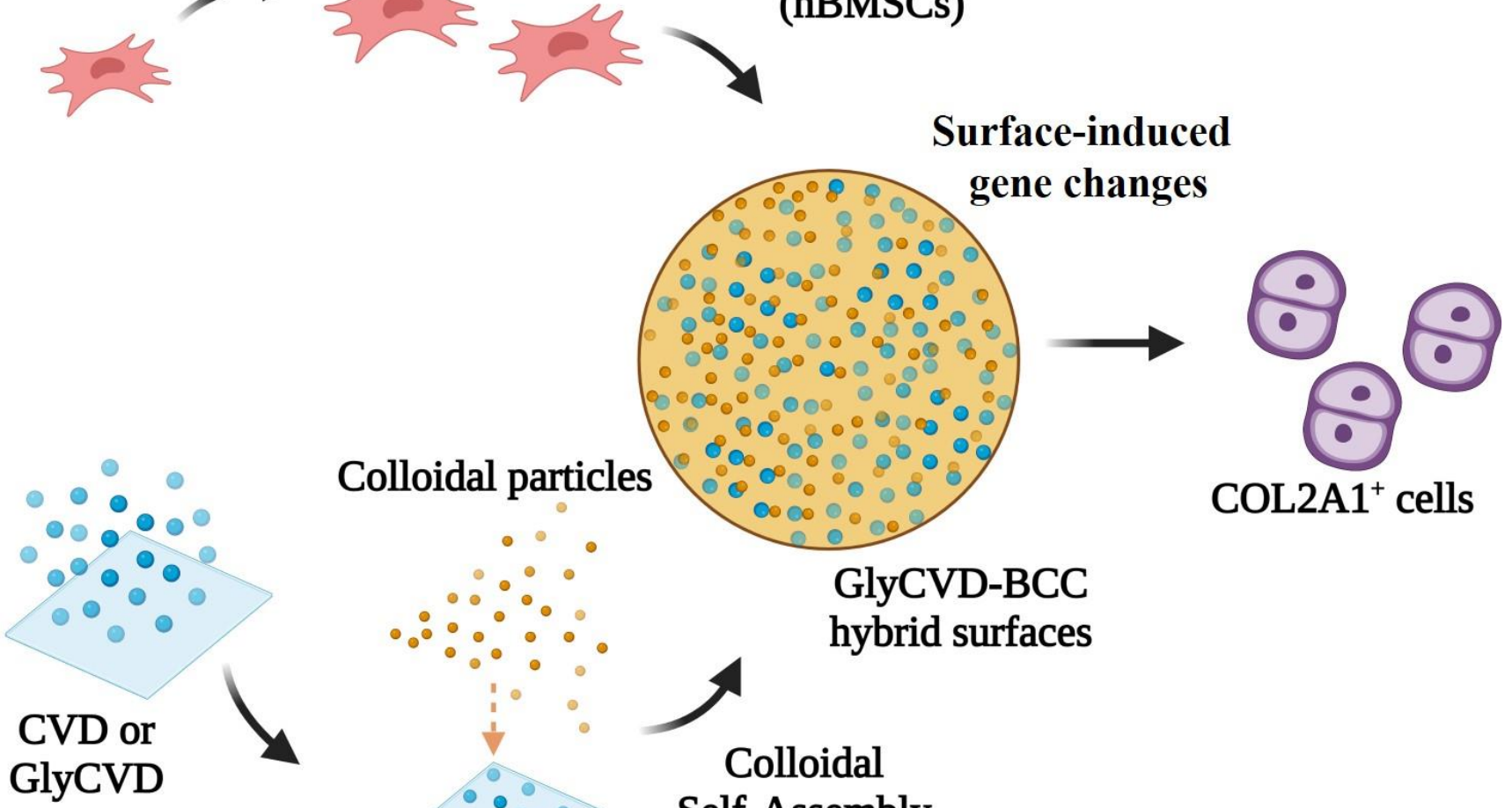

Colloidal particles
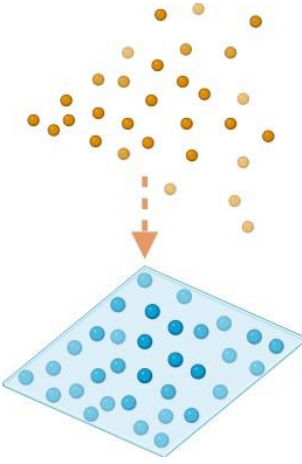

$$
\begin{aligned}
& \text { GlyCVD-BCC } \\
& \text { hybrid surfaces }
\end{aligned}
$$

\section{Colloidal \\ Self-Assembly}

Scheme 1. Scheme of this study. Hybrid structures are, for the first time, fabricated using two technologies, CVD and cSAPs. The surface structure can be tuned by the fabrication process. Unique hierarchical structures are able to be produced. Hybrid surface, especially GlyCVD-BCC, alters cell morphology, growth, and gene expression of human bone marrow stem cells (hBMSCs). Cell morphology is aggregated and the gene expression of COL2A1 is upregulated on the GlyCVD-BCC surface. The study demonstrates the potentiall of combining two coating technologies for the generation of hybrid structures that can stimulate gene expression of hMSCs without chemical induction.

\section{Conclusions}

For the first time, this study combined two nanotechnologies, colloidal self-assembly and CVD, to fabricate hybrid nanostructures. Nanostructures could be tuned using different fabrication conditions, opening the door for the fabrication of new nanostructures. The biomedical function of the hybrid nanostructures was demonstrated using hBMSC culture. 
One hybrid nanostructure, GlyCVD-BCC, could continuously stimulate the COL2A1 gene expression of hBMSCs for 14 days using a standard culture medium. Although the underlying mechanism is still to be answered, cell functions could be affected on the GlyCVD-BCC surface. This study contributes to the fields of biomaterials and bioengineering.

Author Contributions: Conceptualization, H.-Y.C. and P.-Y.W.; methodology, H.-Y.C. and P.-Y.W.; validation, Y.-C.L. and P.-Y.W.; formal analysis, Y.-C.L.; investigation, Y.-C.L., J.-W.J., K.L., H.P.; resources, H.-Y.C. and P.-Y.W.; data curation, Y.-C.L.; writing-original draft preparation, Y.-C.L.; writing-review and editing, Y.-C.L. and P.-Y.W.; supervision, P.-Y.W.; project administration, P.-Y.W.; All authors have read and agreed to the published version of the manuscript.

Funding: This research was funded by the Ministry of Science and Technology of China (the National Key Research and Development Program: 2019YFE0113000), the National Natural and Science Foundation of China (the general program: 31870988), the Chinese Academy of Sciences (172644KYSB20200002 and 172644KYSB20200048), the Department of Science and Technology of Guangdong Province (International Collaborative Project: 2021A0505030055), and the Science, Technology, and Innovation Commission of Shenzhen Municipality (the International Innovation and Collaboration Program: GJHZ20180928115804736), and the Shenzhen Key Laboratory (ZDSYS2019090209 3409851). Y.C. Liu thanks the support from the Chinese Academy of Sciences (Taiwan Young Talent Program: 2019TW2GB0005).

Institutional Review Board Statement: The research in this manuscript did not involve any animal ethics.

Informed Consent Statement: Not applicable.

Data Availability Statement: Not applicable.

Conflicts of Interest: The authors declare no conflict of interest.

\section{References}

1. Chen, F.M.; Liu, X.H. Advancing biomaterials of human origin for tissue engineering. Prog. Polym. Sci. 2016, 53, 86-168. [CrossRef]

2. Bose, S.; Robertson, S.F.; Bandyopadhyay, A. Surface modification of biomaterials and biomedical devices using additive manufacturing. Acta Biomater. 2018, 66, 6-22. [CrossRef] [PubMed]

3. Wu, C.-Y.; Chang, C.-W.; Yuan, R.-H.; Chiang, Y.-C.; Chen, J.-T.; Kang, D.-Y.; Chen, H.-Y. Multifunctional nanoparticles with controllable dimensions and tripled orthogonal reactivity. Nanoscale 2017, 9, 14787-14791. [CrossRef] [PubMed]

4. Tung, H.-Y.; Guan, Z.-Y.; Liu, T.-Y.; Chen, H.-Y. Vapor sublimation and deposition to build porous particles and composites. Nat. Commun. 2018, 9, 2564. [CrossRef]

5. Alf, M.E.; Asatekin, A.; Barr, M.C.; Baxamusa, S.H.; Chelawat, H.; Ince, G.O.; Petruczok, C.D.; Sreenivasan, R.; Tenhaeff, W.; Trujillo, N.J.; et al. Chemical Vapor Deposition of Conformal, Functional, and Responsive Polymer Films. Adv. Mater. 2009, 22, 1993-2027. [CrossRef] [PubMed]

6. Yang, R.; Asatekin, A.; Gleason, K.K. Design of conformal, substrate-independent surface modification for controlled proteinadsorption by chemical vapor deposition (CVD). Soft Matter 2012, 8, 31-43. [CrossRef]

7. Xu, H.; Akbari, M.K.; Zhuiykov, S. 2D Semiconductor Nanomaterials and Heterostructures: Controlled Synthesis and Functional Applications. Nanoscale Res. Lett. 2021, 16, 1-38. [CrossRef]

8. Woo, H.-S.; Na, C.W.; Lee, J.-H. Design of Highly Selective Gas Sensors via Physicochemical Modification of Oxide Nanowires: Overview. Sensors 2016, 16, 1531. [CrossRef]

9. Gorham, W.F. A New, General Synthetic Method for the Preparation of Linear Poly-p-xylylenes. J. Polym. Sci. Part A-1 Polym. Chem. 1966, 4, 3027-3039. [CrossRef]

10. Moss, T.; Greiner, A. Functionalization of Poly(para-xylylene)s-Opportunities and Challenges as Coating Material. Adv. Mater. Interfaces 2020, 7, 1901858. [CrossRef]

11. Lahann, J. Vapor-based polymer coatings for potential biomedical applications. Polym. Int. 2006, 55, 1361-1370. [CrossRef]

12. Chen, P.-R.; Wang, T.-C.; Chen, S.-T.; Chen, H.-Y.; Tsai, W.-B. Development of Antifouling Hyperbranched Polyglycerol Layers on Hydroxyl Poly-p-xylylene Coatings. Langmuir 2017, 33, 14657-14662. [CrossRef] [PubMed]

13. Chen, H.-Y. Micro- and nano-surface structures based on vapor-deposited polymers. Beilstein J. Nanotechnol. 2017, 8, 1366-1374. [CrossRef] [PubMed]

14. Wang, P.-Y.; Pingle, H.; Koegler, P.; Thissen, H.; Kingshott, P. Self-assembled binary colloidal crystal monolayers as cell culture substrates. J. Mater. Chem. B 2015, 3, 2545-2552. [CrossRef] [PubMed]

15. Diba, F.S.; Boden, A.; Thissen, H.; Bhave, M.; Kingshott, P.; Wang, P.-Y. Binary colloidal crystals (BCCs): Interactions, fabrication, and applications. Adv. Colloid Interface Sci. 2018, 261, 102-127. [CrossRef] 
16. Shi, Y.; Lin, J.; Tao, X.; Qu, J.; Liao, S.; Li, M.; Deng, K.; Du, P.; Liu, K.; Thissen, H.; et al. Harnessing Colloidal Self-Assembled Patterns (cSAPs) to Regulate Bacterial and Human Stem Cell Response at Biointerfaces In Vitro and In Vivo. ACS Appl. Mater. Interfaces 2021, 13, 20982-20994. [CrossRef]

17. Cui, C.; Wang, J.; Qian, D.; Huang, J.; Lin, J.; Kingshott, P.; Wang, P.-Y.; Chen, M. Binary Colloidal Crystals Drive Spheroid Formation and Accelerate Maturation of Human-Induced Pluripotent Stem Cell-Derived Cardiomyocytes. ACS Appl. Mater. Interfaces 2019, 11, 3679-3689. [CrossRef]

18. Diba, F.S.; Reynolds, N.; Thissen, H.; Wang, P.; Kingshott, P. Tunable Chemical and Topographic Patterns Based on Binary Colloidal Crystals (BCCs) to Modulate MG63 Cell Growth. Adv. Funct. Mater. 2019, 29, 1904262. [CrossRef]

19. Boden, A.; Bhave, M.; Wang, P.-Y.; Jadhav, S.R.; Kingshott, P. Binary Colloidal Crystal Layers as Platforms for Surface Patterning of Puroindoline-Based Antimicrobial Peptides. ACS Appl. Mater. Interfaces 2018, 10, 2264-2274. [CrossRef]

20. Pingle, H.; Wang, P.; Thissen, H.; Kingshott, P. Controlled Attachment of Pseudomonas aeruginosa with Binary Colloidal Crystal-Based Topographies. Small 2018, 14, e1703574. [CrossRef]

21. Deng, K.; Du, P.; Liu, K.; Tao, X.; Harati, J.; Jhang, J.-W.; Kim, J.; Wang, P.-Y. Programming Colloidal Self-Assembled Patterns (cSAPs) into Thermo-Responsible Hybrid Surfaces for Controlling Human Stem Cells and Macrophages. ACS Appl. Mater. Interfaces 2021, 13, 18563-18580. [CrossRef]

22. Wang, P.-Y.; Thissen, H.; Kingshott, P. Stimulation of Early Osteochondral Differentiation of Human Mesenchymal Stem Cells Using Binary Colloidal Crystals (BCCs). ACS Appl. Mater. Interfaces 2016, 8, 4477-4488. [CrossRef] [PubMed]

23. Wang, P.-Y.; Hung, S.S.-C.; Thissen, H.; Kingshott, P.; Wong, R.C.-B. Binary colloidal crystals (BCCs) as a feeder-free system to generate human induced pluripotent stem cells (hiPSCs). Sci. Rep. 2016, 6, 36845. [CrossRef] [PubMed]

24. Chiang, Y.-C.; Ho, C.-P.; Wang, Y.-L.; Chen, P.-C.; Wang, P.-Y.; Chen, H.-Y. Vapor-Deposited Reactive Coating with Chemically and Topographically Erasable Properties. Polym. 2019, 11, 1595. [CrossRef] [PubMed]

25. Lm, S.J.; Kim, D.; Kim, Y.; Jeong, S.; Pang, C.; Ryu, S.; Weon, B.M. Hydrophobicity Evolution on Rough Surfaces. Langmuir 2020, 36, 689-696. [CrossRef]

26. Niu, Y.; Yu, M.; Meka, A.; Liu, Y.; Zhang, J.; Yang, Y.; Yu, C. Understanding the contribution of surface roughness and hydrophobic modification of silica nanoparticles to enhanced therapeutic protein delivery. J. Mater. Chem. B 2016, 4, 212-219. [CrossRef]

27. Tung, H.-Y.; Sun, T.-P.; Sun, H.-Y.; Guan, Z.-Y.; Hu, S.-K.; Chao, L.; Chen, H.-Y. Construction and control of 3D porous structure based on vapor deposition on sublimation solids. Appl. Mater. Today 2017, 7, 77-81. [CrossRef]

28. Chiu, Y.-R.; Hsu, Y.-T.; Wu, C.-Y.; Lin, T.-H.; Yang, Y.-Z.; Chen, H.-Y. Fabrication of Asymmetrical and Gradient Hierarchy Structures of Poly-p-xylylenes on Multiscale Regimes Based on a Vapor-Phase Sublimation and Deposition Process. Chem. Mater. 2020, 32, 1120-1130. [CrossRef]

29. Zhong, Y.; Meng, F.; Deng, C.; Zhong, Z. Ligand-Directed Active Tumor-Targeting Polymeric Nanoparticles for Cancer Chemotherapy. Biomacromolecules 2014, 15, 1955-1969. [CrossRef]

30. Wang, P.-Y.; Clements, L.R.; Thissen, H.; Jane, A.; Tsai, W.-B.; Voelcker, N.H. Screening Mesenchymal Stem Cell Attachment and Differentiation on Porous Silicon Gradients. Adv. Funct. Mater. 2012, 22, 3414-3423. [CrossRef]

31. Wang, P.-Y.; Thissen, H.; Kingshott, P. Modulation of human multipotent and pluripotent stem cells using surface nanotopographies and surface-immobilised bioactive signals: A review. Acta Biomater. 2016, 45, 31-59. [CrossRef] [PubMed]

32. Dalby, M.J.; Gadegaard, N.; Oreffo, R.O.C. Harnessing nanotopography and integrin-matrix interactions to influence stem cell fate. Nat. Mater. 2014, 13, 558-569. [CrossRef] [PubMed]

33. Olsen, L.A.; Nicoll, J.; Fry, A.C. The skeletal muscle fiber: A mechanically sensitive cell. Graefe's Archive for Clinical and Experimental Ophthalmology 2019, 119, 333-349. [CrossRef]

34. Fruleux, A.; Hawkins, R.J. Physical role for the nucleus in cell migration. J. Phys. Condens. Matter 2016, 28, 363002. [CrossRef] [PubMed]

35. Chang, R.; Yan, Q.; Kingshott, P.; Tsai, W.-B.; Wang, P.-Y. Harnessing the perinuclear actin cap (pnAC) to influence nanocarrier trafficking and gene transfection efficiency in skeletal myoblasts using nanopillars. Acta Biomater. 2020, 111, 221-231. [CrossRef] [PubMed]

36. Lee, I.-C.; Liu, Y.-C.; Shen, C.-N.; Chang, Y.-C.; Tsai, H. Promoting the Selection and Maintenance of Fetal Liver Stem/Progenitor Cell Colonies by Layer-by-Layer Polypeptide Tethered Supported Lipid Bilayer. ACS Appl. Mater. Interfaces 2014, 6, 20654-20663. [CrossRef]

37. Dufour, S.; Mege, R.M.; Thiery, J.P. Alpha-Catenin, Vinculin, and F-Actin in Strengthening E-Cadherin Cell-Cell Adhesions and Mechanosensing. Cell Adh. Migr. 2013, 7, 345-350. [CrossRef]

38. Biggs, M.J.P.; Richards, R.G.; Dalby, M.J. Nanotopographical modification: A regulator of cellular function through focal adhesions. Nanomed. Nanotechnol. Biol. Med. 2010, 6, 619-633. [CrossRef]

39. Kolind, K.; Dolatshahi-Pirouz, A.; Lovmand, J.; Pedersen, F.S.; Foss, M.; Besenbacher, F. A combinatorial screening of human fibroblast responses on micro-structured surfaces. Biomaterials 2010, 31, 9182-9191. [CrossRef]

40. Nematollahi, M.; Hamilton, D.; Jaeger, N.; Brunette, D. Hexagonal micron scale pillars influence epithelial cell adhesion, morphology, proliferation, migration, and cytoskeletal arrangement. J. Biomed. Mater. Res. Part A 2009, 91A, 149-157. [CrossRef]

41. Deng, Y.; Tan, X.-T.; Wu, Q.; Wang, X. Correlations BetweenCOL2AandAggrecanGenetic Polymorphisms and the Risk and Clinicopathological Features of Intervertebral Disc Degeneration in a Chinese Han Population: A Case-Control Study. Genet. Test. Mol. Biomark. 2017, 21, 108-115. [CrossRef] [PubMed] 
42. Jokoji, G.; Maeda, S.; Oishi, K.; Ijuin, T.; Nakajima, M.; Tawaratsumida, H.; Kawamura, I.; Tominaga, H.; Taketomi, E.; Ikegawa, S.; et al. Cdc5l Promotes Early Chondrocyte Differentiation and Proliferation by Modulating Pre-Mrna Splicing of Sox9, Col2a1, and Wee1. J. Biol. Chem. 2021, 297, 100994. [CrossRef] [PubMed]

43. Li, S.; Stockl, S.; Lukas, C.; Gotz, J.; Herrmann, M.; Federlin, M.; Grassel, S. Hbmsc-Derived Extracellular Vesicles Attenuate Il-1beta-Induced Catabolic Effects on Oa-Chondrocytes by Regulating Pro-Inflammatory Signaling Pathways. Front. Bioeng. Biotechnol. 2020, 8, 603598. [CrossRef] [PubMed]

44. Weng, J.-J.; Su, Y. Nuclear matrix-targeting of the osteogenic factor Runx2 is essential for its recognition and activation of the alkaline phosphatase gene. Biochim. Biophys. Acta (BBA)-Gen. Subj. 2012, 1830, 2839-2852. [CrossRef] [PubMed]

45. Arufe, M.; De la Fuente, A.; Fuentes-Boquete, I.; De Toro, F.J.; Blanco, F.J. Differentiation of synovial CD-105+human mesenchymal stem cells into chondrocyte-like cells through spheroid formation. J. Cell. Biochem. 2009, 108, 145-155. [CrossRef]

46. Mennan, C.; García, J.; McCarthy, H.; Owen, S.; Perry, J.; Wright, K.; Banerjee, R.; Richardson, J.B.; Roberts, S. Human Articular Chondrocytes Retain Their Phenotype in Sustained Hypoxia While Normoxia Promotes Their Immunomodulatory Potential. Cartil. 2018, 10, 467-479. [CrossRef]

47. Du, P.; Tao, X.; Liu, K.; Lin, J.; Shi, Y.; Park, K.; Chen, H.-Y.; Lin, C.-P.; Chang, J.; Wong, R.C.; et al. Human platelet lysate (hPL) alters the lineage commitment and paracrine functions of human mesenchymal stem cells via mitochondrial metabolism. Appl. Mater. Today 2021, 26, 101264. [CrossRef]

48. Le, H.T.-N.; Ngoc, B.V.; Phuc, D.-N.N.; Thuy, T.-T.D.; Xuan, H.-V.T.; Phuc, V.P. Production of Engineered Cartilage from Mesenchymal Stem Cell Spheroids. Front. Biosci.-Landmark 2021, 26, 266-285.

49. Soteriou, D.; Iskender, B.; Byron, A.; Humphries, J.D.; Borg-Bartolo, S.; Haddock, M.-C.; Baxter, M.A.; Knight, D.; Humphries, M.J.; Kimber, S.J. Comparative Proteomic Analysis of Supportive and Unsupportive Extracellular Matrix Substrates for Human Embryonic Stem Cell Maintenance. J. Biol. Chem. 2013, 288, 18716-18731. [CrossRef]

50. Tan, Q.; Lui, P.P.Y.; Rui, Y.F. Effect of In Vitro Passaging on the Stem Cell-Related Properties of Tendon-Derived Stem Cells-Implications in Tissue Engineering. Stem Cells Dev. 2012, 21, 790-800. [CrossRef]

51. Saha, S.; Ghosh, P.; Mitra, D.; Mukherjee, S.; Bhattacharya, S.; Roy, S. Localization and Thyroid Hormone Influenced Expression of Collagen II in Ovarian Tissue. Cell. Physiol. Biochem. 2007, 19, 67-76. [CrossRef] [PubMed]

52. Llontop, P.; Santana-Rodríguez, N.; Clavo, B.; Quintana, A.; Fiuza, M.D.; Camacho, R.; Santana-Rodríguez, A.; Santana, C.; Ruíz-Caballero, J.A. Stem Cells Protect the Bronchial Stump in Rat, Increasing Sox6, Col2a1, and Agc1 Expression. Lung 2014, 192, 441-448. [CrossRef] [PubMed]

53. Horton, E.R.; Vallmajo-Martin, Q.; Martin, I.; Snedeker, J.; Ehrbar, M.; Blache, U. Extracellular Matrix Production by Mesenchymal Stromal Cells in Hydrogels Facilitates Cell Spreading and Is Inhibited by FGF-2. Adv. Healthc. Mater. 2020, 9, e1901669. [CrossRef] [PubMed]

54. Ding, S.; Kingshott, P.; Thissen, H.; Pera, M.; Wang, P.-Y. Modulation of human mesenchymal and pluripotent stem cell behavior using biophysical and biochemical cues: A review. Biotechnol. Bioeng. 2017, 114, 260-280. [CrossRef]

55. Zhang, H.; Zheng, X.; Ahmed, W.; Yao, Y.; Bai, J.; Chen, Y.; Gao, C. Design and Applications of Cell-Selective Surfaces and Interfaces. Biomacromolecules 2018, 19, 1746-1763. [CrossRef] [PubMed]

56. Karimi, F.; O'Connor, A.J.; Qiao, G.G.; Heath, D.E. Integrin Clustering Matters: A Review of Biomaterials Functionalized with Multivalent Integrin-Binding Ligands to Improve Cell Adhesion, Migration, Differentiation, Angiogenesis, and Biomedical Device Integration. Adv. Healthc. Mater. 2018, 7, e1701324. [CrossRef] [PubMed]

57. Shi, Y.; Liu, K.; Zhang, Z.; Tao, X.; Chen, H.-Y.; Kingshott, P.; Wang, P.-Y. Decoration of Material Surfaces with Complex Physicochemical Signals for Biointerface Applications. ACS Biomater. Sci. Eng. 2020, 6, 1836-1851. [CrossRef] 